\title{
Entero-paraspinous fistula from recurrent spinal metastatic renal cell carcinoma
}

\author{
Ambur Reddy, MD, ${ }^{1}$ Patrick W. Hitchon, MD, ${ }^{1}$ Sami AI-Nafi, MD, ${ }^{1}$ and Kent Choi, MD² \\ Departments of ${ }^{1}$ Neurosurgery and ${ }^{2}$ Surgery, University of lowa Carver College of Medicine, lowa City, lowa
}

The authors report a case of entero-paraspinous fistula 2 years after T-12 corpectomy and instrumentation for spinal metastasis from renal cell carcinoma. The pathogenesis in the present case seems to have arisen from local recurrence of T-12 metastatic carcinoma in spite of radiation and corpectomy. As a result of previous nephrectomy and anterolateral dissection for the T-12 corpectomy, the jejunum adhered to the surgical site. Recurrent tumor at T-12 invaded the adherent small bowel loop, resulting in a fistulous communication between the small bowel lumen and the spinal wound. Loss of retroperitoneal fat, scarring, and adhesions from previous surgeries contributed to this complication by having the jejunum close to the T-12 corpectomy site, and eventually to its invasion by recurrent tumor. Avoidance of such a complication is difficult; however, total excision of the spinal malignancy, and when possible, creating a barrier cuff of fascia or fat around the spine to protect abdominal contents, are potential solutions.

http://thejns.org/doi/abs/10.3171/2014.10.SPINE14294

KEY WORDS anterior spinal instrumentation; entero-spinal fistula; spinal metastatic tumor; oncology

$\mathrm{C}$ OMPLICATIONS following anterior thoracolumbar spinal instrumentation are infrequent in spite of the frequency with which this approach is undertaken. Reports of complications are estimated at less than 5\%.3,6,12 These complications can be classified as acute ${ }^{3,6,12}$ or delayed. ${ }^{5,8}$ These complications include bowel and vascular injuries, neurological deficit, spinal fluid leaks, and infections. ${ }^{2,5,8}$ Entero-spinal fistula 2 years after corpectomy and instrumentation for metastatic renal cell carcinoma is a very rare clinical presentation. To our knowledge, there is no such case report documented in the English-language scientific literature.

\section{Case Report}

This 66-year-old man had been diagnosed with a renal cell carcinoma in 1998 and underwent a left nephrectomy. At that time, Stage T1 renal cancer was diagnosed, and the patient remained disease free for 11 years. In 2009 the patient presented with a T-12 vertebral body lesion (Fig. 1). This was initially treated with a course of radiation therapy, but after time his condition worsened with increasing back pain. Ultimately, because of progression of his symptoms and enlargement of his tumor, the patient underwent a T-12 corpectomy through a left flank approach. Anterior column reconstruction was performed using a carbon fiber reinforced polymer cage (DePuy Spine) with anterior T11-L1 screw and rod fixation (Fig. 2). Contemporaneous T9-L3 posterior instrumentation was also performed, and the patient had an unremarkable postoperative course.

Two years later, the patient presented with fever of $102^{\circ} \mathrm{F}$, C-reactive protein of 28.3 , sedimentation rate of 118 , and tenderness over his spinal surgical wound. Body CT scanning (Fig. 3) showed a loop of jejunum close to the fusion hardware at T-12. Air was noted also in the right paravertebral soft tissues, suggestive of fistulous communication with the jejunum. On examination, the patient had erythema and induration along the midline surgical scar on his back measuring $4 \times 10 \mathrm{~cm}$ that was tender to palpation but did not break the skin. Ultrasound revealed a large, complicated fluid collection overlying the lower thoracic spine under the previous surgical wound. The fluid collection was predominantly isoechoic with multiple hyperechoic foci of air internally, measuring at least $5 \mathrm{~cm}$ in the craniocaudal dimension and at least $2.2 \times 1.2 \mathrm{~cm}$ in the transverse and anteroposterior dimensions. This was aspirated and yielded acellular debris with abundant bacteria and rare fungal forms.

An exploratory laparotomy was performed with findings of a jejunal fistula communicating between the small

SUBMITTED March 20, 2014. ACCEPTED October 13, 2014.

INCLUDE WHEN CITING Published online November 14, 2014; DOI: 10.3171/2014.10.SPINE14294.

DISCLOSURE Patrick W. Hitchon is the recipient of research support for the Neurosurgery Biomechanics Laboratory from DePuy Spine, Raynham, MA. No financial support was received for this project. 

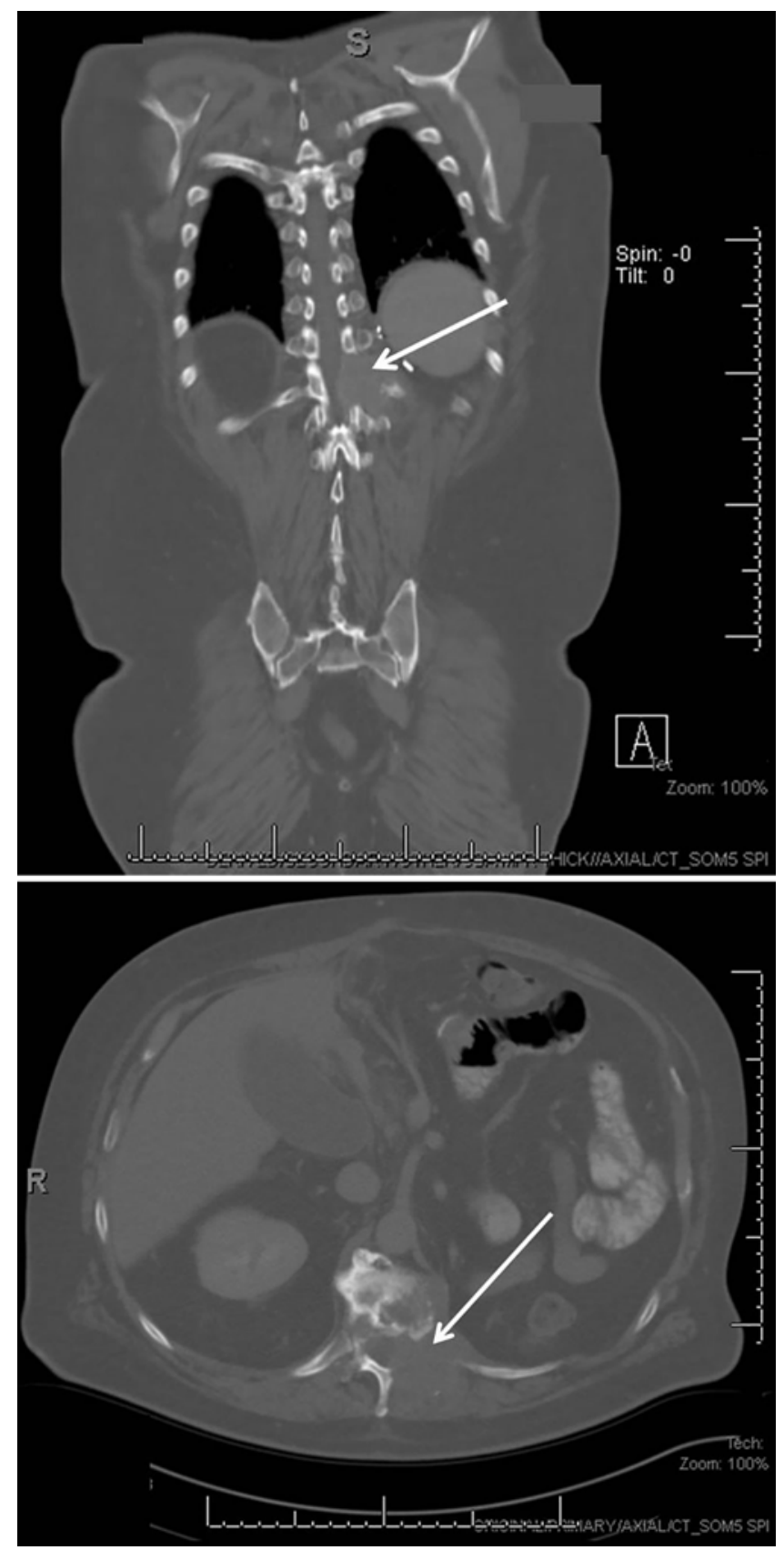

FIG. 1. Coronal (upper) and axial (lower) CT scans of the spine showing metastatic tumor (arrows) to T-12 on the left with erosion of the left side of the body, pedicle, and facet.

bowel and left paraspinous area adjacent to the hardware, with the spinal hardware on the left side of the spine soaked in enteric contents. This was successfully treated with small bowel resection (Fig. 4) and primary bowel anastomosis. The omentum was mobilized to provide coverage over the exposed spinal hardware. After closure of the flank wound, the patient was turned prone and underwent debridement of the back wound with primary closure, leaving the hardware in place. Histopathological examination of the resected bowel revealed metastatic renal carcinoma, clear cell type, involving the serosa and muscularis propria and abutting the mucosa. This finding
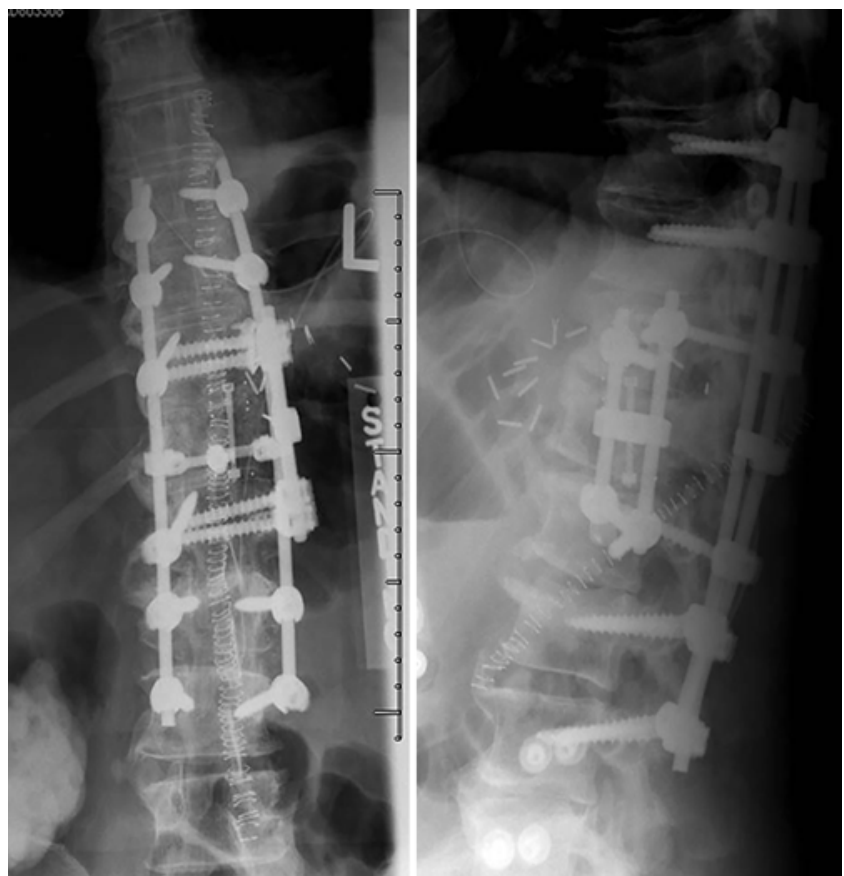

FIG. 2. Anteroposterior (left) and lateral (right) plain radiographs showing the anterior and posterior hardware for decompression and stabilization.

suggested that the tumor developed from local disease advancement from the spinal lesion to the adjacent small bowel loop. Cultures grew Escherichia coli, Klebsiella pneumoniae, Streptococcus viridans, Clostridium perfringens, Prevotella buccae, Bacteroides vulgatus, and yeast. The patient was treated with oral fluconazole 800 $\mathrm{mg}$ daily, ciprofloxacin $500 \mathrm{mg}$ every 12 hours, and metronidazole $500 \mathrm{mg} 3$ times a day for 2 months. He was discharged to skilled care and eventually went home with hospice care. He was ambulatory and received physical therapy, with his pain adequately controlled with Tylenol without opiates. Eventually, the patient developed other areas of metastases to the abdomen, lungs, and skeleton and required narcotic analgesics. He spent the last 2 months in skilled care under hospice and died 1 year later.

\section{Discussion}

After a thorough literature search on similar cases, we are confident that this is the first written case report for an entero-paraspinal abscess. There have been rare reports of spinal epidural abscesses developing in the setting of inflammatory bowel disease. ${ }^{1}$ Two documented cases of rectothecal fistula have been reported, ${ }^{9,11}$ one due to a ruptured anterior sacral meningocele and another in a case of traumatic injury to the rectum during L5-S1 anterior fixation.

The pathogenesis in the present case seems to have arisen from local recurrence of T-12 metastatic renal cell carcinoma in spite of radiation and corpectomy. As a result of previous nephrectomy and anterolateral dissection for the T-12 corpectomy, the jejunum adhered to the surgical site. Recurrent tumor at T-12 invaded the adherent small bowel loop, resulting in a fistulous communication 

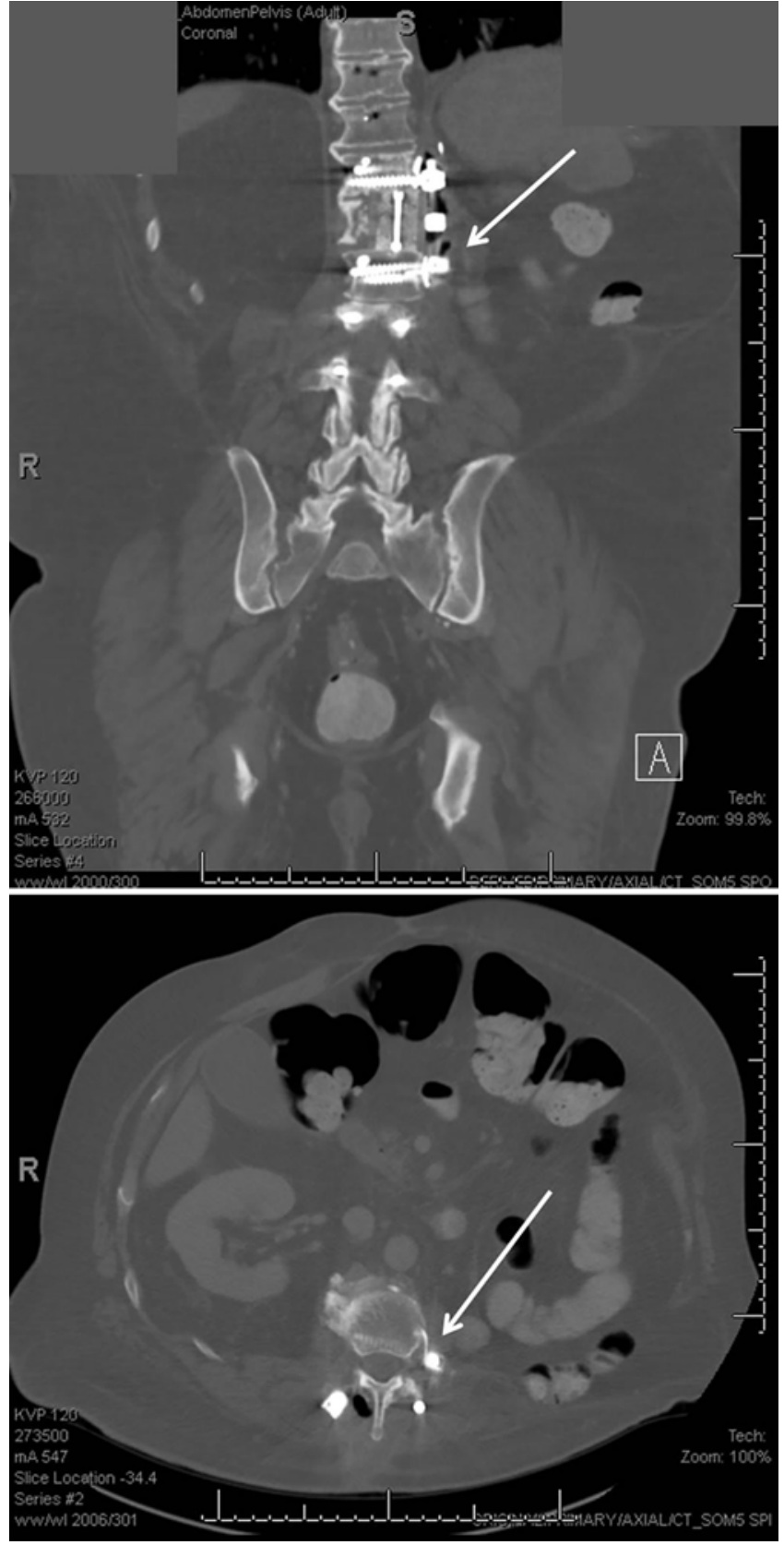

FIG. 3. Coronal (upper) and axial (lower) CT scans demonstrating air on both sides of the spine (arrow, upper), with small bowel adherent to the spine (arrow, lower), creating the fistulous tract.

between the small bowel lumen and the spinal wound. Loss of retroperitoneal fat, scarring, and adhesions from previous surgeries contributed to this complication by having the jejunum close to the T-12 corpectomy site, and eventually to its invasion by recurrent tumor.

Complications arising from anterior thoracolumbar instrumentation are quite infrequent and are estimated at less than 5\%., ${ }^{3,6,12}$ The infrequency of this complication is the fact the majority of these implants are placed deep to the psoas muscle, thereby protecting the abdominal viscera and vessels from injury. The rarity of these complications is also attributed in part to the selection of rela-

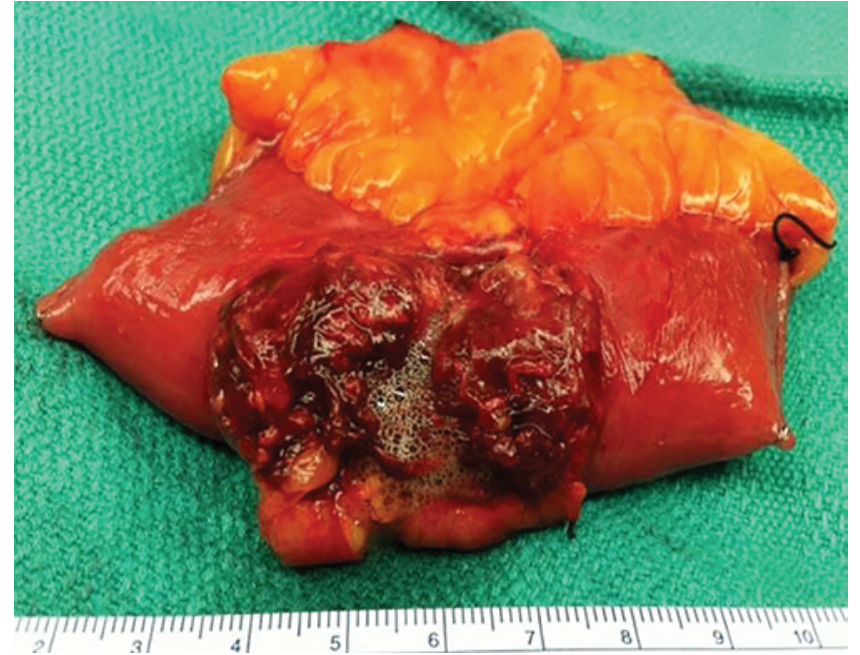

FIG. 4. Photograph of the resected small bowel segment with renal cell carcinoma invading the entire wall. Figure is available in color online only.

tively low-profile implants. ${ }^{8}$ Delayed complications after anterior spinal surgery and instrumentation have been reported. Aortic erosion occurred 3 weeks after surgery for stabilization of an L-2 burst fracture with paraplegia in a 25-year-old man. ${ }^{5}$ The patient presented with abdominal distention and anemia. Abdominal films revealed a shift of abdominal contents. Six days later the patient became hypotensive and underwent exploration and repair of the aortic laceration. The aorta was seen pulsating against the high-profile anterior prosthesis. Following repair and removal of the device, the patient made an uneventful recovery. A similar erosive process, though involving the large bowel, has been reported. ${ }^{8}$ In that case, a 53-year-old woman underwent posterior L4-S1 pedicle screw fixation followed by anterior L4-S1 instrumentation. The anterior strut graft consisted of a mesh cage packed with bone, and the anterior instrumentation comprised single pedicle screws in each of L-4 and S-1 with an interposing single rod. Five years later the patient presented with bleeding per rectum and a hemoglobin of $4 \mathrm{~g} \%$. She was found to have sigmoid colon perforation by the rod and erosion of the left common iliac artery by the L-4 anterior screw. The anterior implant was removed, and bowel resection and arterial reconstruction were performed. The eventual recovery was excellent. Both of the aforementioned reports on delayed complications were attributed to high-profile implants adjacent to viscera.

Considering the proximity of spinal malignancy and anterior spinal implants to vessels and bowel loops, it is perhaps more surprising than not that such perforations are not encountered more commonly. In general, bowel loops are not anchored but move within the abdomen. This lack of adherence of the bowel to the spine contributes to the extremely low prevalence rate for this problem. We do not think this unique case presentation could have been prevented in any way. However, our report demonstrates that a true entero-spinal fistula is indeed possible, especially in the setting of an aggressive neoplastic process and postoperative scarring. It is strongly advised that anterior spinal implants should be imbedded in the psoas 
muscle whenever possible to distance the implant from abdominal viscera. When that is not possible, it has been suggested that the implant should be covered with a cuff of fat or fascia covering the spine or implant for avoidance of such erosions or invasion. ${ }^{8}$ Insofar as the hardware is concerned, in view of the aggressive nature of the cancer, prior radiation therapy, and current infection, we felt that the hardware was best left in place to minimize surgery. Eradication of infection with debridement and antibiotics in the presence of hardware has been demonstrated in several reports. ${ }^{4,7,10}$

\section{Acknowledgment}

We thank Faith Vaughn for her invaluable assistance in the preparation and editing of this manuscript.

\section{References}

1. Brown CJ, Jaffer H, Jaffer N, Burul C, McLeod RS: Spinal epidural abscess - a rare complication of inflammatory bowel disease. Can J Gastroenterol 22:177-180, 2008

2. Campbell PG, Malone J, Yadla S, Maltenfort MG, Harrop JS, Sharan AD, et al: Early complications related to approach in thoracic and lumbar spine surgery: a single center prospective study. World Neurosurg 73:395-401, 2010

3. Faciszewski T, Winter RB, Lonstein JE, Denis F, Johnson L: The surgical and medical perioperative complications of anterior spinal fusion surgery in the thoracic and lumbar spine in adults. A review of 1223 procedures. Spine (Phila Pa 1976) 20:1592-1599, 1995

4. Hegde V, Meredith DS, Kepler CK, Huang RC: Management of postoperative spinal infections. World J Orthod 3:182189,2012

5. Jendrisak MD: Spontaneous abdominal aortic rupture from erosion by a lumbar spine fixation device: a case report. Surgery 99:631-633, 1986

6. Kaneda K, Asano S, Hashimoto T, Satoh S, Fujiya M: The treatment of osteoporotic-posttraumatic vertebral collapse using the Kaneda device and a bioactive ceramic vertebral prosthesis. Spine 17 (8 Suppl):S295-S303, 1992

7. Kasliwal MK, Tan LA, Traynelis VC: Infection with spinal instrumentation: Review of pathogenesis, diagnosis, prevention, and management. Surg Neurol Int 4 (Suppl 5):S392S403, 2013

8. Keerthi I, Dhillon CS, Shetty MB: Late-onset bowel perforation and iliac artery erosion after prominent anterior spinal instrumentation. Spine (Phila Pa 1976) 37:E1402-E1405, 2012

9. Koksal A, Canyigit M, Kara T, Ulus A, Gokbayir H, Sarisahin M: Unusual presentation of an anterior sacral meningocele: magnetic resonance imaging, multidetector computed tomography, and fistulography findings of bacterial meningitis secondary to a rectothecal fistula. Jpn J Radiol 29:528531,2011

10. Levi AD, Dickman CA, Sonntag VKH: Management of postoperative infections after spinal instrumentation. J Neurosurg 86:975-980, 1997

11. Siegel G, Patel N, Ramakrishnan R: Rectocutaneous fistula and nonunion after TranS1 axial lumbar interbody fusion L5-S1 fixation. Case report. J Neurosurg Spine 19:197-200, 2013

12. Wood KB, Devine J, Fischer D, Dettori JR, Janssen M: Vascular injury in elective anterior lumbosacral surgery. Spine (Phila Pa 1976) 35 (9 Suppl):S66-S75, 2010

\section{Author Contributions}

Conception and design: Reddy. Acquisition of data: Hitchon, Reddy, Choi. Drafting the article: Hitchon, Reddy. Critically revising the article: Al-Nafi.

\section{Correspondence}

Patrick W. Hitchon, Department of Neurosurgery, University of Iowa Carver College of Medicine, 200 Hawkins Dr., 1826 JPP, Iowa City, IA 52242. email: patrick-hitchon@uiowa.edu. 